\title{
Recommendations of Polish Society of Physiotherapy, Polish Society of Family Medicine and College of Family Physicians in Poland for hip joint pain in primary health care
}

\author{
KRZYSZTOF KASSOLIK ${ }^{1,2, ~ D-F}$, ELŻBIETA RAJKOWSKA-LABON ${ }^{1,3, \mathrm{D}-\mathrm{F}}$, TOMASZ TOMASIK ${ }^{4,5, \mathrm{D}-\mathrm{F}}$, \\ AGNIESZKA PISULA-LEWADOWSKA ${ }^{2, D-F}$, KRZYSZTOF GIEREMEK ${ }^{1,6, D-F}$, \\ WALDEMAR ANDRZEJEWSKI ${ }^{1,2, ~ D-F}$, DONATA KURPAS ${ }^{4,7,8, ~ D-F}$
}

${ }^{1}$ Polish Society of Physiotherapy, Poland

${ }^{2}$ Department of Physiotherapy, Academy of Physical Education in Wroclaw, Poland

${ }^{3}$ Department of Physiotherapy, Medical University of Gdansk, Poland

${ }^{4}$ College of Family Physicians in Poland

${ }^{5}$ Department of Family Medicine, Chair of Internal Diseases and Gerontology, Jagiellonian University Medical College in Krakow, Poland

${ }^{6}$ Academy of Physical Education in Katowice, Poland

${ }^{7}$ Polish Society of Family Medicine, Poland

${ }^{8}$ Department of Family Medicine, Wroclaw Medical University, Poland

A - Study Design, B - Data Collection, C - Statistical Analysis, D - Data Interpretation, E - Manuscript Preparation, F - Literature Search, G - Funds Collection

Summary Background. The authors share the view that the treatment of degenerative changes concerning the hip is a multidisciplinary activity. In the opinion of the authors, in the physiotherapeutic procedure, the order of developing periarticular structures is important when restoring normal homeostasis (blood supply, oxygenation, tonus, nutrition), in the area of the joint where there is a modified distribution of resting tension of soft tissues. Patient condition improvement, especially in those with less severe symptoms of degenerative disease (yet are without significant structural changes in the joint and without functional limitations), seems to be the most justified at the level of services provided by the primary care physician.

Objectives. The objective of this recommendation for hip joint physiotherapy within the basic health care stage is to propose a simple, uncomplicated set of physiotherapeutic actions that would allow, in particular at the first stage of change, the performance of activities decelerating degenerative processes in this joint and, hence, limiting the pain. The publication is a proposal for a new model of patient care in the system of Polish primary health care, and it is intended to form a background for systemic solutions (including the creation of an interdisciplinary cooperation model) that could be implemented.

Material and methods. Experts from the Polish Society of Physiotherapy, the Society of Family Medicine and the College of Family Physicians have reviewed published evidence from 2008-2018 regarding the use of physiotherapy in treating degenerative changes of the hip joint that have been placed online in PubMed and Cochrane Collaboration.

Conclusions. Maintaining good efficiency in hip joint pain patients is the priority in the treatment proceedings. Achievement of the above mentioned goal is possible through improvement of the accessibility of health services, the introduction of early (basic) therapeutic actions (education and physioprophylaxis) and actively engaging patients in the rehabilitation process (self-therapy) as conducted by the physiotherapist and the individual patient in cooperation with a primary care physician. Shaping a health-conscious attitude within primary care patients, the slowing down of disease progression and the postponing more advanced treatment forms are all further benefits resulting in reduction of the treatment costs within the healthcare system.

Key words: physicians, primary health care, physical therapy specialty, hip joint.

Kassolik K, Rajkowska-Labon E, Tomasik T, Pisula-Lewadowska A, Gieremek K, Andrzejewski W, Kurpas D. Recommendations of Polish Society of Physiotherapy, Polish Society of Family Medicine and College of Family Physicians in Poland for hip joint pain in primary health care. Fam Med Prim Care Rev 2018; 20(2): 183-193, doi: https://doi.org/10.5114/fmpcr.2018.76465.

\section{Background}

Degenerative joint changes (OA - osteoarthritis), including the hip joint (coxarthrosis), are among the musculoskeletal disorders that are a frequent problem of an aging society. OA evidences a growing economic burden as well as a challenge for current medicine and health care. The extension of life span and the increased life quality expectations have become a superior problem in ensuring health, and are now a priority in implementing targeted prophylactic programs all over the world [1].
Hip joints are most frequently exposed to joint degenerative processes due to their anatomic structure, their location, as well as their complex biomechanics [2]. Furthermore, hip joints, similarly to knee joints, are the most exploited supporting joints in the motor organ $[3,4]$. Indeed, OA frequency qualifies this disease to membership within the group of social diseases of the motor organ. Herein, progressing pathology brings about incorrect load distribution within the entire kinematic chain of the lower limb, pelvis and spine.

Clinical examination and imaging still play an important role in the diagnosis of degenerative changes. However, in addition 
to traditional imaging methods (X-ray), specialist care levels offer new technologies and computer aided methods to support analysis ( $\mathrm{MRi}$ - magnetic resonance, $\mathrm{CK}$ - computer tomography, USG), which provide complete and precise pathological imagery in patients [5].

According to the below-mentioned ethology, pathogenesis and clinical imagery of the hip joint $\mathrm{OA}$, it is recommended (as stated by the authors of this paper) that physiotherapeutic procedures be implemented at the initial period when the joint pain occurs. Herein, an important issue is the sequence in which the periarticular structures are worked out so as to restore correct homeostasis (circulation, oxygenation, tonus and nourishing), near the joint, wherein there is an altered distribution of the soft tissue stationary tension. Therefore, when programming the therapy process, it is initially required to include massage, physiotherapy and then exercises and other activity forms.

From the clinical point of view, it is important at each stage of the disease advancement that the patient starts his or her rehabilitation before any irreversible structural changes occur within the hip joint area. It is thus essential to notice the first symptoms related to decrease of muscular flexibility, including periodical pains and weakening, as well as lower strength in muscles that externally pull and rotate the hip [6]. As noticed by Harris-Hajes et al., proper recognition of the disorder causes at the earliest stages (to differ between muscular and articular causes before starting therapy) may potentially delay development of the structural changes in the muscles which provide dynamic and passive resistance in reaction to any external forces [7]. Correct stabilization influences proper articular connection and axial alignment. Moreover, the same restricts exposure to the risk of damage in the articular labrum, the bag and the ligamentous structures, as well as the development of instability in the joint [8]. Receptor pain (capsular-myofascial) constitutes a less complex problem in the therapy in relation to treatment of the pain of structural origin which accompanies the chronic process. Early start of physiotherapeutic procedures, before any structural changes appear or at their slight advancement, will allow to decelerate the degenerative process, reduce pharmacological treatment cost, improve the patient's awareness of auto-therapy and limit disability, thus will unburden the health care system from excessive costs and the need for prolonged therapy [9].

The 21 recommendations developed by the DELPHI discussion panel (represented by experts in rheumatology, orthopaedics and physiotherapy, as well as by patients themselves) indicated, among other issues, that physical activity and loss of body mass are priority preservative actions in this extent. Moreover, regular physical activity and individual exercise programs (including muscle strengthening, cardiovascular activity and flexibility exercises) bring about real chances to lower the pain, decrease the progress of the joint degenerative disorder and improve performance of daily functions [10].

The rehabilitation process success depends not only on the proposed rehabilitation methods, but also on the patient's knowledge and the availability of health care services. In their publication, Smink et al. indicate that in the Netherlands, the primary medical care physician holds the significant role in the care of patients with degenerative changes. The authors also underline that insufficient attention is given to system-based solutions, to supporting the patients by education, to changing their lifestyle and to encouraging them to follow suitable diets in order to control their BMI [11]. Hofstede et al. also emphasis the significance of the primary care physicians in guiding patients with degenerative changes. Furthermore, they notice that orthopaedists recommend improper (too early) qualification to the endoprosthetics without prior exhaustive use of the preserving treatment methods, including pharmacological, physiotherapeutic, dietetic and that related to the change of lifestyle $[12,13]$.
The authors of this paper share the view that hip related degenerative change treatment is a multi-disciplinary action (it needs an integrated operation between physician, physiotherapist, dietitian and psychotherapist) [14]. All in all, improving the health status of patients, in particular, those with less advanced degenerative disease symptoms (still without major functional limitations), seems undoubtedly justified at the level of the primary medical care physician.

\section{Objectives}

The objective of this recommendation for physiotherapy for hip joint pain in basic health care is to propose simple, uncomplicated physiotherapeutic actions that would allow, in particular, at the first stage of change occurrence, to perform activities that decelerate degenerative processes in this joint and which limit the pain. Such is particularly important when prompt access to specialized physicians and specialized health centers is restricted.

\section{Recommendation development method}

Experts of Polish Society of Physiotherapy, Polish Society of Family Medicine and College of Family Physicians performed a detailed review of any published evidences from the years 2008-2018 concerning the use of physiotherapy with regard to hip joint degenerative changes as placed in the data bases PubMed and Cochrane Collaboration. The aforementioned were browsed using the keywords: hip osteoarthritis, pain, risk factors, epidemiology, guidelines, therapeutic exercise. The prepared synthesis was further analyzed by the experts with respect to usefulness in the Polish primary health care system and to the system-based solutions (including development of the interdisciplinary collaboration model) that could be implemented in our country. The possibility of implementing the model of proceeding at the basic care level and supported by physiotherapy, in patients with pain in the said joints, is, hence, presented.

\section{Epidemiology}

Data analysis for 1996 indicated that $9.6 \%$ of all men and $18 \%$ of all women all over the world, at the age of 60 and older, have some joint degenerative issues. The largest patients share was found in developed regions of the world [15]. American-sourced data reveal that $\mathrm{OA}$ is the main disability reason in persons after 65 . Indeed, in nearly $40 \%$ of all persons above 65 and in $85 \%$ of all individuals above 75 years some joint degenerative symptoms are evident $[15,16]$. Estimated data from Australia indicate that among all age groups, the OA frequency is higher in women than in men (respectively, 2.95 vs 1.75 per 1000 persons) [9].

European researches show that the OA frequency in women is $13 \%$ and it is $8 \%$ in men at the age of $45-49$. Moreover, this frequency increases with age. Among persons 80 years old, this problem applies to $55 \%$ of the total population [15]. In Sweden, hip joint degenerative change in persons above 45 is recognized via radiologic testing in $2.3 \%$ of all women and $1.9 \%$ of all men [9]. It is estimated in the European population, the number of persons with the OA problem will increase from 75 million in 2005, to 135 million in 2050. This means that every third Europe inhabitant will be potentially exposed to degenerative changes, including that in the hip joints [17].

In Poland, according to Central Statistical Office calculation, the number of persons above 65 years will double and exceed 8 million. It must be expected then that such an increase of elder persons in the population will also involve higher numbers of OA cases [17]. 
The progression of degenerative changes in the hip joint is in particular related to some limitation in everyday functioning, and the aforementioned is the common indication for complete replacement surgery of the hip joint. In the United States, within the last 20 years, the number of patients operated upon due to necessity to replace the joint increased from 286,324 in 1996, to 369,372 in 2006 , to 464,452 in 2011 (http://hcupnet.ahrq. gov) [18].

\section{Ethiopatology}

The hip joint degenerative disorder pathogenesis process is not completely understood, and researches are still conducted to find the so-far-unknown causes of degenerative disease. At the OARSI (Osteoarthritis Research Society International) Congress in 2017, it was underlined that it is required to include in this quest new technologies found in diverse research fields, including genetics, engineering, nanotechnology and nuclear medicine bioselective indicators - all of which could contribute to the pathophysiological insight [19]. Results from these researches will help, for example, more effectively eliminate the pain (depending on the disease clinical stage and the pain phenotype), and also better identify potential causes of joint function disability [19].

Current opinion prevails on a multi-factor ethiopathogenesis with regard to hip joint degenerative disease [20]. The disease causes may be conditioned by metabolic dysfunction or by excessive pathologic load on the joint. Damage of the joint cartilage is a result of a disproportion in activity between degenerative enzymes (from the metalloproteinases group) in relation to those responsible for its regeneration (growth factors (TFGß), insulin-like growth factor (IGF) and tissue inhibitors of metalloproteinases (TIMP)) [4, 20, 21]. Researches performed by Achedi et al. indicate that damage of the joint cartilage in the $\mathrm{X}$-ray image of 2 degree in both genders and of 1 degree (mainly in men) are related to clinical, demographic and structural factors essential for OA. The joint cartilage damage in the hip joint, according to the researchers, may be one of major causes of fast advancement of the disease and the pathophysiology. This opinion, however, requires confirmation in further observations [22].

Among the other reasons for degenerative changes, they mention incorrect biomechanical loads directed on the hip joints during different occupational activities related to lifting, handling, climbing stairs or ladders, with or without weights [23]. The researches performed demonstrate that the most burdened is the ipsilateral hip joint (located at the same body side) during lifting and switching the load side from one to another in a horizontal plane. Herein, research results indicate that excessive loads directed on the hip may result in increased pressure on the joint cartilage, and can provoke degenerative changes [23].

In the investigation of Magnus, it was observed that the chance of hip joint degenerative changes risk doubled (OR 2.0; $95 \% \mathrm{Cl} 1.5-2.8$ ), and also the hip joint arthoplasty was 2.5 times more frequent (OR $2.5 ; 95 \% \mathrm{Cl} 1.6-3.7$ ) in former athletes than in a control group [24]. Moreover, the available researches demonstrate that male athletes taking part in elite sports at the national or professional level (football, handball, rugby, athletics or hockey) feature increased risk of the hip joint OA development, while persons participating in long distance runs have no explicitly increased risk [25].

The meta-analysis (credibility of evidences at 2 a level), published in the JOSPT issue of 2017, indicate that differences in exposure to the hip or knee degenerative changes depend on the run frequency and intensity. General frequency of the hip and knee joint OA was $13.3 \%$ (95\% Cl: $11.6 \%, 15.2 \%)$ in competitors with high training load, $3.5 \%(95 \% \mathrm{Cl}: 3.4 \%, 3.6 \%)$ in recreational runners and $10.2 \%(95 \% \mathrm{Cl}: 9.9 \%, 10.6 \%)$ in the control group.
The rate of chances for hip and/or knee OA in competitors was higher than in joggers or to results received in the control group (in non-runners or persons of sedentary lifestyle) [26].

Researches by Lefèvre-Colau et al. indicate that the OA risk in a radiological image (more frequent presence of osteophytes, without the features of joint space narrowing) is increased in persons who undertake regular and intensive training. Exposed to the said changes are competitors in team, strength and contact sports. To a lesser extent, this applies to those who train in endurance sports and in running races. However, everyday recreational or sport activities with moderate intensity, regardless of their type, are not a fixed factor of clinical or radiological risk of the knee/hip OA [27]. The rate of clinical advancement and the disease development will depend on the balance between the cartilage synthesis and its degradation. Progressing changes will affect both the joint and the surrounding tissues.

Taking into account all of the above aspects, it must be ascertained whether the mentioned causes are directly related to $\mathrm{OA}$ and if they may be modified through physician-directed therapy or conduct [8].

\section{a) Influence of myalgic origin factors}

It is noticed that the disease development is influenced by periarticular muscles atrophy or weakening (that may involve disorder of protective reactions, joint hypermobility and instability), leading to increased risk of microtrauma in the joint cartilage being the cause of degenerative changes. Such muscle weakening, featuring a decrease of their strength or their motor unit activation, may lead to changes in walking and to lower capacity in everyday activities [1]. In other research, it was also found that development of clinical symptoms, regardless of hip joint OA advancement, is related to atrophy, weakening of glutes and restriction of abduction range in this joint. Interpretation of changes in glutes mass, according to the authors, may be a useful tool for clinicians that plan rehabilitation strategies for patients [28]. Moreover, it must be added that peak muscular mass is reached in about the $30^{\text {th }}$ year of life. After this period it is reduced at the rate $3-8 \%$ per decade, and even greater loss takes place after the $60^{\text {th }}$ year of life [16]. In 2002, the results of the National Health Interview Survey (NHIS) in the USA confirmed that the patients with diagnosed OA had lesser levels of physical activity in relation to the general population. Indeed, $37 \%$ of the population with this diagnosis were physically inactive [29].

\section{b) Changes in X-ray image}

In the radiological image, the level of degenerative change advancement and progression is assessed based on the IRF (Individual Radiographic Feature) scale. The assessment includes the joint space width, the presence and size of ostheophytes or cysts, sclerotisation of the subchondral layer and maintenance of the joint alignment [30]. Of note, since muscles ensure dynamic joint stability during motion, some indications of degenerative changes (such as ostheophytes and rim thickening) may hypothetically be the result of trials taken by the organism to increase joint stability in situations of inefficient muscle performance that eventually lead to joint instability in movement [8]. Other symptoms seen via X-ray image include: sclerotisation of the subchondral bone layer, osseous cysts (so-called, degenerative geodes), exostosis cartilaginea, ostheophytes, mushroom-deformity of the femoral head, doubling of the bottom of the acetabulum and apparent shortening of the femoral neck [31].

\section{c) Disturbed blood distribution and joint nourishing}

Both correct function and the healing process require appropriate blood distribution. The hip joint area is supplied with 
arterial blood both through the branches of the internal iliac artery and the external iliac artery. The neck of femur, together with the head, is supplied by branches coming from the external hip artery, while the acetabulum is supplied from branches coming from the obturator artery and the inferior and superior gluteal artery that are extensions of the internal iliac artery. Blood supply disorder may initiate degenerative disorders around the hip joint. Both in the osseous tissue, as well in the cartilage or the connective tissue that create ligaments, the articular capsule or the circumferential cartilage, the process of replacing its component, mainly collagen fibers, is continued constantly. This is a base for adaptive, regenerative and repair processes within the joint area. In situations wherein the arterial blood supply is restricted and the outflow of the venous blood and the lymph is obstructed, the regenerative processes may be decelerated and degenerative changes may occur. At the same time, such scenarios may favor the occurrence of increased stress and pain in the muscles via restriction of their capacity. An example may be the piriformis muscle or the iliococcygeus muscle. In the event of increased piriformis muscle stress, further disturbances of the artery blood distribution may appear. This is induced by pressure on the superior gluteal artery coming from under the joint (a.o., the artery branching to the acetabulum and to the iliopsoas muscle) and to the inferior gluteal artery (that ensures blood supply, a.o. for the sciatic nerve), whilst the iliopsoas has key importance for the efficiency of the lumbar plexus that comes through it. The same, the blood supply disturbance and increased muscular stress that persists for longer time, may lead to pain and even to the inclusion of neuralgia, and significantly accelerates the creation of degenerative changes within hip joint periarticular tissues. Of note, the use of different forms of thermal treatment without prior normalizing of the piriformis and the iliopsoas may sometimes bring an opposite effect in the form of pain intensification [2].

\section{d) Incorrect function of circumferential cartilage}

The anatomic element that affect function disorder and pain is the circumferential cartilage. Its correct structure tightens the joint and secures optimal hydrostatic fluid tension in the intra-articular space. This mechanism humidifies the joint and protects it against damage. The circumferential cartilage acts as a girth for the joint during walking and prevents its excessive widening [32]. In addition, the joint unsealing leads to a decrease of its surface consolidation. Recent researches have demonstrated that the circumferential cartilage includes numerous proprioreceptors and nociceptors. The biggest cluster of the mentioned receptors is seen in the anterior part - which correlates with more frequent changes in this area [2].

\section{e) Incorrect axial load in the joint}

A joint load that is considered incorrect in accordance with biomechanical rules generates an accelerated wear condition of the articular cartilage. In researches (Dandacheli et al. 2008) with the use of the TK 3D approach, the authors gave differences in the cover of correct and dysplastically changed femur heads, that were, respectively, $75 \%$ vs $51 \%$. Herein, it must be recognized that damage to the articular cartilage results in pain and joint dysfunction [33]. Furthermore, incorrect biomechanical loads accelerate the process of cartilage structure wear, and it was observed in conducted researches that the capsules in women have a greater tendency to ante-version than that in men [34]. In addition, incorrect alignment of the head in the capsule brings about the potential risk of degenerative disease.

\section{Clinical picture}

Joint degenerative disease is one of main causes of pain and disability in the adult population. It is estimated that 27 million people in the United States and 8.5 million people in the United Kingdom have clinically diagnosed degenerative changes. Herein, OA in at least one joint, is presented in $13.9 \%$ of all persons at the age of 25 and older and in $33.6 \%$ of all adults at the age of 65 and older [35]. The disease process affects all articular tissues (i.e. cartilage, synovium, membranes, meniscuses and ligaments), as well as the periarticular tissues (tendons, fat tissue and muscles). The aforementioned tissues undergo metabolic, structural and functional changes that contribute to initiation and increase chronicity of pain, hence facilitating the disease progress and leading to disability [36]. The disease process usually starts from changes in the cartilage or in the subchondral layer, however, the patient's clinical picture depends on the rate of affected peripheral and intra-articular structures. As a consequence of disturbed blood pressure and incorrect biomechanical loads on the hip joints, local pain intensifies, capsule-muscle contractures fixate within the joint area, muscle mass loss progresses, and lower limb movability is gradually restricted. This last affects dysfunction in other joints (knee, ankle and lower lumbar spine) and enhances the disturbed balance. Most difficult for the patient is the fact that his or her locomotion is limited, and that efficiency gradually worsens (through gradual increase of stiffness and greater functional limitations) [4, 37].

In patients with degenerative changes of the hip joint, the pain is often an irreversible element of everyday activity. Moreover, its intensity depends on the disease advancement and progress rate, and it initially intensifies during activity, thus discouraging any exercise. Along with tiredness and rigidity, with time, it is more and more difficult to mobilize for motion, and additional activity is inhibited and limited to a necessary minimum. Pain is, thus, the key determinant of the kinesiphobia that leads to sedentary lifestyles and decreased general efficiency, as well as to an increase of the risk of obesity and cardiovascular diseases [10].

A vicious cycle is, thus, created: on the one hand, lack of activity; on the other hand, progress of the disease, resulting in increasing loss of the joint motion extent and the intensifying of pain. In addition, more factors appear that worsen the patient's general condition: becoming overweight or obese, aging, weakening, lacking in energy, experiencing progressive loss of fitness. Further barriers mentioned by the patients in researches that determine activity are lack of motivation and purpose, as well as feelings of boredom, laziness, lack of time and family interaction. Moreover, the examined persons held that recommendations for activity were not compliant with their adopted lifestyle and were in contradiction to their social roles. In addition, some patients demonstrated attitudes of resignation from any effort due to feelings of helplessness and because of the necessity to adapt to a reality related to decreased functional efficiency [38].

Persons with increased pain syndrome, while standing, keep their hip and knee joint slightly bent so as to lower the articular capsule tension. They also balance their lower limbs on their toes, thus avoiding the lowering of their pelvis. Herein, increased pain syndrome is accompanied by increased tension and painfulness of the quadratus plantae muscle and the inferior constrictor muscle of the pharynx (and in consequence, it brings about a possible irritation of the lumbar plexus) and the quadriceps straight head. Additionally, in the sitting position they move body weight to the counter lateral of their hip and restrict their lower limb rotation (intensifying the tension of the piriformis muscle and in consequence generating pressure upon the superior and inferior gluteal artery). What is more, they bend in a characteristic way to avoid excessive extension in their hip joint [39]. Significant problems appear during stair climbing/ /descending or when moving along areas with diverse inclination, and also when getting in and out of vehicles. Prosaic activities like putting on socks, shoes or changing positions when sleeping, become quite a challenge due to stiffness and pain. At changes with lesser intensity, initially disturbed patterns of walking appear (variation in limb positioning in adduction, as 
well as external rotation usually caused by intensified tension in muscles and adduction of the hip due to protective hip joint positioning and possible irritation of the obturator nerve within the inferior constrictor of pharynx or obturator externus). The disease progress leads to limping, and then it is necessary to use orthopedic provisions (one or two bullet ulnas).

Palpation assessment is very useful in determining which muscles show increased tension at rest, or show reduced flexibility and lowered strength of note, when pressing on the muscular trailer, it may be assumed that in cases of increased tension at rest, this place will be painful $[40,41]$.

\section{Differential diagnostics for the needs of physiotherapy}

Physiotherapists may perform differential diagnosis by clinical tests [6] - palpation assessment of the pressure sensitivity in muscles and ligaments is presented in Table 1.

\section{Physiotherapeutic strategy}

\section{a) Objectives}

The care program for patients with hip joint pain is aimed to reach and maintain functional efficiency and independence so as to ensure good quality of life. As for now, no conclusive guidelines have been developed for the type of exercises, their intensity (load, duration, number of repeats) with regard to hip joint degenerative changes. Proposed forms of activity are different, so it is sometimes difficult to compare their effectiveness against each other [43]. The intention of taken rehabilitation activities is to overcome current, troublesome disease symptoms, i.e. pain or limited functional capacities, so to halt or at least decelerate the progress of the pathology in the joint [4]. The objective is also to reduce treatment costs in the health care system. The therapy must take into account the patient's needs, as well as his or her preferences, both physical and emotional. A key element of such physiotherapy is possible prompt implementation of targeted physiotherapeutic actions (including rehabilitation, education and physioprophylactics). This may be ensured only by primary health care-givers. Researches concerning the analyses of health behaviors indicate that the investigated persons found no relation between active lifestyle, diet and their influence on the risk of occurrence and progression of the joint degenerative changes [44].

Other researches performed by Veenhof et al. demonstrate that persons with degenerative changes avoid any activity due to pain. In turn, insufficient activity, particularly in the initial period, weakens the muscle strength. This leads to joint instability and is a real risk factor for these changes. The authors indicate that when degenerative changes of the hips and knees occur, physical activity is particularly recommended for persons who are overweight, at older age, not active or show reduced functional efficiency [45]. Patients underline that factors motivating activity were support from medical personnel such as the physiotherapist's professional supervision during exercises (hence, credible qualifications, knowledge, instructions, education, positive relationships with the patient) and the physician's engagement (provision of guidelines, recipes, generation of a positive health experience). Among environmental factors that encourage active lifestyles, they mentioned group exercises (socialization element), as well as support from family and friends [38].

WHO-Europe stresses the importance of education in the therapeutic process, and strongly infers that patient education is a continuous process, being an integral element of health-care. The aforementioned includes awareness, provision of information, learning and psychosocial support. All elements of this process are related to the disease and its treatment [46].

\begin{tabular}{|c|c|c|c|}
\hline Muscle & $\begin{array}{l}\text { Place of palpation } \\
\text { assessment }\end{array}$ & Place of pain & Effect on vessels and nerves \\
\hline $\begin{array}{l}\text { Piriformis and gluteal } \\
\text { medius }\end{array}$ & $\begin{array}{l}\text { End trailer on bigger } \\
\text { trochanter of femur }\end{array}$ & Buttock pain & $\begin{array}{l}\text { Pressure on superior and exterior hypophysial artery } \\
\text { that in consequence may lead to disturbed blood supply } \\
\text { in the hip, acetabulum, and disorder of sciatic nerve } \\
\text { function }\end{array}$ \\
\hline Iliopsoas muscle & $\begin{array}{l}\text { Lesser trochanter (dif- } \\
\text { ficult access). When } \\
\text { the lumbar plexus is } \\
\text { irritated by the inferior } \\
\text { constrictor muscle of the } \\
\text { pharynx, the pain often } \\
\text { appears when pressing } \\
\text { on the superior surface } \\
\text { of the tibia } \\
\end{array}$ & $\begin{array}{l}\text { Pain in the hip and me- } \\
\text { dial knee area, increased } \\
\text { tension in hip adducting } \\
\text { muscles }\end{array}$ & $\begin{array}{l}\text { Irritation of lumbar plexus, and also obturator nerve, } \\
\text { femoral nerve }\end{array}$ \\
\hline $\begin{array}{l}\text { Obturator externus } \\
\text { muscle }\end{array}$ & $\begin{array}{l}\text { End trailer in femur over } \\
\text { trochanter pit (difficult } \\
\text { access - only when lying } \\
\text { on side) }\end{array}$ & $\begin{array}{l}\text { Painfulness when press- } \\
\text { ing on hip adducting } \\
\text { muscles. } \\
\text { Pain in knee medial area }\end{array}$ & $\begin{array}{l}\text { Pressure on obturator nerve inferior branch that inner- } \\
\text { vate hip adducting muscles }\end{array}$ \\
\hline Head straight quadriceps & $\begin{array}{l}\text { Initial trailer on anterior } \\
\text { inferior iliac spine }\end{array}$ & $\begin{array}{l}\text { Pain in groin and knee } \\
\text { anterior area }\end{array}$ & $\begin{array}{l}\text { Increased tension of this muscle has no significant effect } \\
\text { on vessels and nerves }\end{array}$ \\
\hline Hip adducting muscles & $\begin{array}{l}\text { Median hip area } \\
\text { (10 cm above knee joint } \\
\text { space) }\end{array}$ & Pain in medial hip part & $\begin{array}{l}\text { Increased tension of hip adducting muscles and possible } \\
\text { irritation of obtuator nerve by obturator internus } \\
\text { muscle, thorough which runs inferior branch of obtua- } \\
\text { tor nerve, or by inferior constrictor muscle of pharynx, } \\
\text { through which runs lumbar plexus, also including } \\
\text { obturator } n\end{array}$ \\
\hline Gluteus maximus muscle & $\begin{array}{l}\text { Gluteal tuberosity of the } \\
\text { femur }\end{array}$ & Pain in buttocks area & \\
\hline Tensor fasciae latae & $\begin{array}{l}\text { Anterior superior iliac } \\
\text { spine }\end{array}$ & $\begin{array}{l}\text { Pain in hip lateral surface } \\
\text { within the ilio tibial band } \\
\text { anterior part }\end{array}$ & $\begin{array}{l}\text { Increased tension on anterior iliac spine may lead to } \\
\text { intensified tension of inguinal ligament and pressure on } \\
\text { hip lateral sural nerve that runs through this ligament }\end{array}$ \\
\hline
\end{tabular}




\section{b) Selection of treatment methods}

Since the causes that trigger hip joint degenerative disease pain, deformation, and in consequence, disability, are complex, the rehabilitation program must go beyond the area of only local action. Therefore, the counter to hip pain consists in applying both pharmacological and non-pharmacological treatment methods in order to slow down degenerative changes [39].

From the patient's health assessment, including palpation $[47,48]$, the examiner can determine which muscles and fasciae should be worked first to restore the correct function of vessels and nerves in the hip joint area. The aforementioned include:

- the piriformis muscle - responsible for the correct function of the superior and exterior hypophysial artery and the sciatic nerve,

- the iliopsoas muscle - responsible for correct function of the lumbar plexus,

- the obturator externus muscle - responsible for correct function of the obturator nerve inferior branch.

Long-lasting increased tension in the above muscles may lead to functional disorder of the superior and exterior hypophysial artery that play important roles in blood supply to most of the hip girdle, and as well to the acetabulum and the sciatic nerve. Therefore, the physiotherapeutic strategy in the hip joint pain should first focus on normalization of increased muscle tension, and only then on restoring correct trophy within the hip joint and on improving its functions.

\section{Massage}

Massage should be used in basic medical care, both as a short-term activity and as a long term activity. In short term therapy, massage is applied for normalization of muscles tension at rest and to restore correct trophy in the fasciae, muscles, ligaments, tendons and articulate capsulas. In long term therapy it is applied usually as self-massage (performed by the patient alone) to inhibit decline processes in the muscles, tendons, ligaments and fasciae by initiating agiogenesis processes and boosting processes of replacing collagen fibers in the connective tissue that create the above motor system organs.

The main source of blood supply for the hip joint muscles and periarticular tissues is the internal iliac artery, and, more precisely, its branches: the inferior and superior gluteal artery, the obturator artery and the iliolumbar artery (which sometimes comes off the superior gluteal artery) [2]. The muscles that due to long-lasting increased tension may disturb the function of the above arteries include: obturator externus - through which in addition runs the obturator nerve inferior branch that innervates the hip adducting muscles and the piriformis muscle (from under which comes out a.o. the sciatic nerve and the inferior and superior gluteal artery). Any physiotherapeutic action in the area of the hip joint, whether the application of kinesiotherapy and physioterapeutic procedures, or different forms of massage, should be started from the normalization of the piriformis muscle tension, as well as that of the obturator externus and internus. Due to difficult access to these muscles, the best form of relaxation is the massage, which through normalization of the muscles, fascia and ligaments evokes easier accessibility, being structurally correlated with the piriformis muscle and obturators, and enables the normalization of their tension at rest. As a result of the above, the pressure upon vessels and nerves is relieved and the correct blood supply in the area of the hip joint is restored. Moreover, pain is significantly reduced (pain being an effect of poor blood supply to tissues), as is the neuralgia that is a result of irritating the obturator nerve, the sciatic nerve, and, in extreme cases, also the lumbar plexus. After such relief, the exercises and therapeutic procedures which are integral part of both prophylactic proceedings, as well as the total therapeutic program may be started $[14,55]$.

\section{Physiotherapy}

Pain is a complex phenomenon that is influenced by a number of biological, psychological and social factors. The cumulation of the aforementioned factors decides on the pain intensity, suffering and disability rate. Pain treatment is most effective when a multi-discipline approach is used. This includes both pharmacological and non-pharmacological approaches. Indeed, the American College of Rheumatology and the American Pain Society recommends aerobic exercises and physiotherapy in persons with rheumatological diseases, including OA [52].

Physical treatment support symptomatic therapy includes relieving pain, blood supply disorders, muscle weakening, edema and inflammation). Herein, physical energy is used to achieve the therapeutic effect. Physiotherapy, the application of which supports healing, includes many forms of therapy such as electrotherapy, thermotherapy (heat, cold), ultrasound and light therapy [56].

The physiotherapy objective with regard to hip joint degenerative changes will consist of inducing an analgesic effect, improving tissue nourishing by better blood supply, hindering muscle losses and preventing or decelerating pathological changes [57]. Types of physical stimuli must be selected individually for each patient, taking into account any contraindications. Preferably, the application should be in one series and include treatments with various stimuli (e.g. electrotherapy, thermotherapy, light-therapy). Physical procedures may also constitute preparation for other therapeutic impact, e.g. massage or kinesiotherapy, hence, the sequence of treatments will be very important, depending on the therapeutic target set and the abilities of the physiotherapeutic laboratory. Physical procedures recommended for hip joint pains induced by OA include electrotherapy (such as TENS) $[3,57,60]$, thermotherapy (local warmth and cold) $[57,58]$ and ultrasounds $[57,59]$.

\section{Kinesthetic rehabilitation}

Our present knowledge level does not allow our therapeutic practices to effectively hinder structural change progression. According to the European League Against Rheumatism (EULAR) and the American College of Rheumatology (ACR), degenerative disease such as $\mathrm{OA}$ is omnidirectional. Herein, treatment includes non-pharmacological therapy and pharmacotherapy, with surgery as a last resort [3].

Treatment and rehabilitation effectiveness very often depends on the change advancement rate, and the success of rehabilitation is contingent on the period elapsed from the first symptoms to the time when rehabilitation was started [61]. Effective treatment is often individually tailored. The guidelines derived in the period of 2008-2014, from various health sources, namely: NICE (The National Institute for Health and Care Excellence), RACGP (The Royal Australian College of General Practitioners), Physical Medicine and Rehabilitation (SOFMER), AAOS (American Academy and Orthopedic Surgeons, ACR, EULAR (European League Against Rheumatism, OARSI (Osteoarthritis Research Society International, ESCEO (The European Society for Clinical and Economic Aspects of Osteoporosis, Osteoarthritis and Musculoskeletal Diseases) indicate that at the 1b level, non-pharmacological treatment include diverse exercises, education, reduction of body mass and enhancement of change biomechanics [16]. Exercises that contribute to reducing pain, stiffness and disability or improve hip joint function and life quality include: aerobic training, endurance exercises, joint mobilizing exercises, stretching exercises, aerobic exercises with low and medium load, proprioception exercises, isometric exercises, resistance exercises, aquatic exercises, as well as conventional exercises (land-based). The last include: mat exercises, isometric, isokinetic, belt and tubing resistance exercises, stretching, walking training (sidewards, forwards, backwards, with rising knee) $[16,18,43,51]$. 


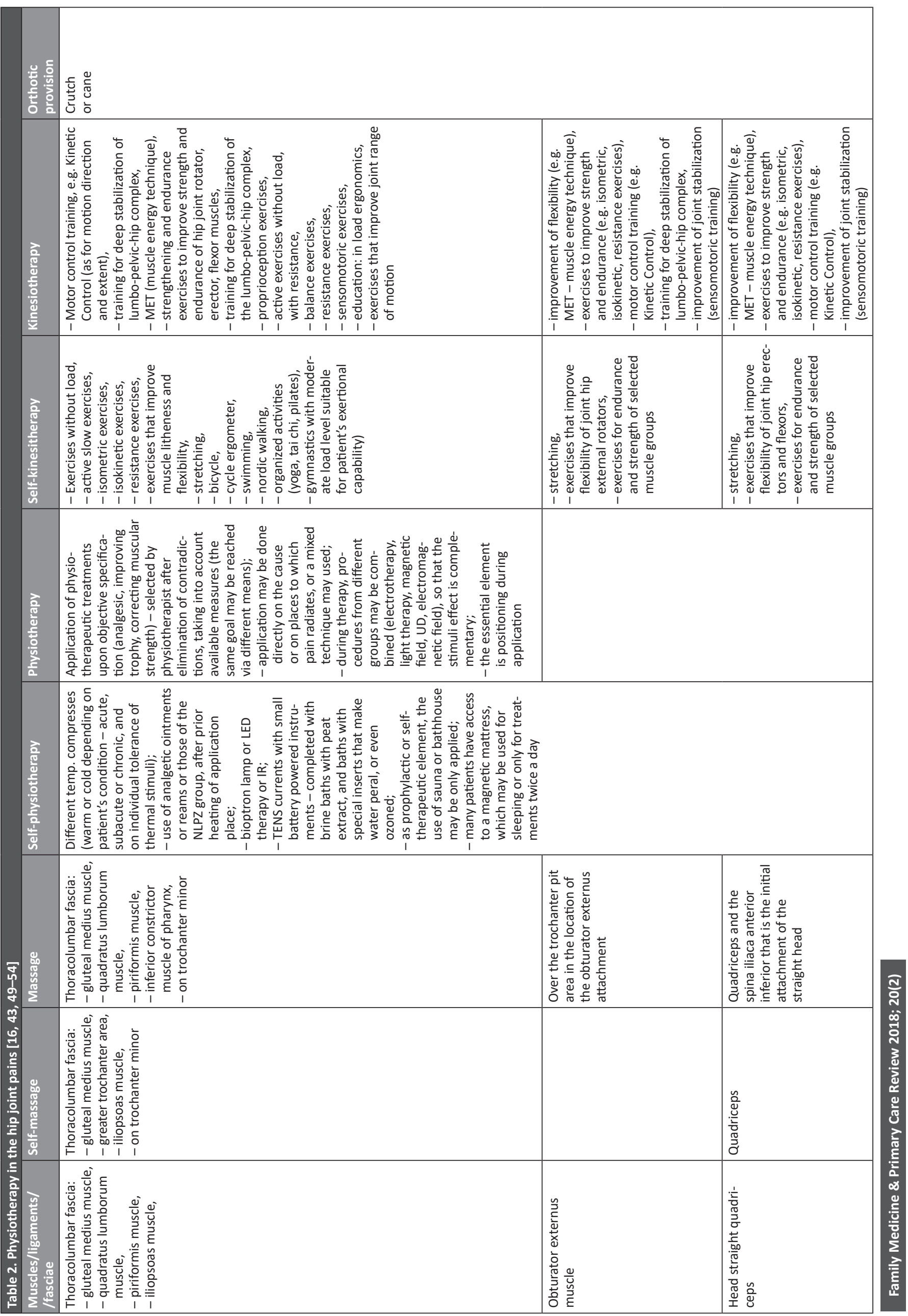


Recent research about treating degenerative changes has focused upon non-pharmacological therapy. The objective of such therapy is to educate the patient about his/her condition, especially towards modifying their life-styles with respect to physical activity level and body mass reduction. Such type of care should be realized based on individual needs, taking into account the disease etiology and accompanying co-existing diseases [19, 52, 54, 62, 63].

Therapeutic exercises are especially relevant in conservative strategies for dealing with degenerative changes. Such activities are, in reality, both prophylactic and therapeutic, and are highly recommended. Therapeutic exercises include aerobics, aquatic reinforcing exercises and tai chi. Routine performance of the aforementioned have positive effects on symptoms, i.e. pain, loss of motion, weakness and depression. In the current literature, however, it is not possible to compare the effectiveness of applied exercises in terms of type, intensity, duration and frequency. From the clinical point of view, it seems that a key element for the success of the therapy is to determine before its start such components as optimal dosage, program customization need, patient abilities and preferences, co-existent diseases, and accessibility of rehabilitation $[37,52,64]$. The study of Regnaux et al. published in 2015, in Cochrane Database of Systematic, remarks upon the lack of report of unwanted reactions (injuries, falls while exercising) in patients while undertaking applied therapy of either low or high intensity. The researchers underline the need for further investigations to determine both the minimal intensity of exercise program needed to reach the clinical effect, as well as highest possible load tolerated with regard to the affliction that still guarantees the patient's security [65].

All exercises should be applied gradually, be suitably proportioned and reflect the patient's preferences and predispositions. Of note, in some persons with OA (especially for hips and knees), the results of rehabilitation are poorer than expected. Researchers suspect that this fact is correlated with other diseases, i.e. overpressure, obesity, diabetics type II and heart diseases [37]. Advantages resulting from the realized exercise program include among others: pain stoppage or relief, improved joint move-ability, increased strength of weakened muscle groups, better proprioception and fitness, reduced risk of falls, better control of body weight, increased cardio-vascular efficiency, lack of or no need for immediate surgery [66, 67]. Some activities with moderate load are regarded as beneficial for joints as they improve the circulation of the synovial, and, at the same time, ensure appropriate supply of nutritional substances to the cartilage. Moreover, they strengthen muscles around the joint [27].

The benefits from physical activity were seen in the studies of Hootman et al. Herein, 5283 adult persons were observed, and after 12.8 years, the examination was repeated. The performed analysis indicated that free-time physical activity (walking, running, jogging, bicycling, swimming, racket sport playing) and moderate or intensive pursuits (i.e., stretching exercises, gymnastic-rhythmic exercises, weight training), did not increase the risk of degenerative change in the hip and knee joints, regardless of the type and volume of activity (intensity, duration, frequency and type of deformation) [68].

Recommendations for the use of selected methods are based on analyzing available evidences and clinician consensus so as to ensure treatment advantages and the patient's safety. Australian recommendations for non-pharmacological treatment of degenerative changes indicate that there are advantages that are related with reduction of body mass. Each lowering by ca. $5 \%$, has positive influence on decrease of pain intensity and disability. The guidelines put forth a series of recommendations based on credibility. Herein, recommendation level B (credible proofing of the applied method efficiency) included supervised rehab exercises, while recommendation level C (evidences with lesser credibility) embodied aquatic exercises (especially for overweight or obese persons), multi-model phys- iotherapy programs (including strengthening exercises, stretching, mobilization, soft tissue work, tai chi, education programs and physical treatment (TENS currents, thermotherapy and acupuncture) [69]. The performed meta-analysis by Fransen et al. (Cochrane Colaboration 2014) demonstrate that scientific evidence confirms the effectiveness of supervised exercises in patients with hip joint degenerative changes. Benefits include pain reduction, improved function and heightened physical fitness. Moreover, these positive effects were maintained 3-6 months after finishing the therapy. Still confirmation of permanency of effect is needed [67].

\section{Orthopedic provision}

In cases of hip joint pain induced by overload or by early degenerative changes of the joint structures, the aim of orthopedic provision is to reduce the joint load. In such situations, the patient should be provided with a cane or crutch or Zimmer frame, to be used periodically or all the time depending on the tissue changes advancement [54, 70-72].

\section{Conclusions}

Maintaining good efficiency in patients with hip joint pain is the priority in all treatment proceedings. Physiotherapy has shown itself to be very effective in this regard. Scientific literature provides evidences for rehabilitation effectiveness, hence reduce concerns about the role of used methods in patient functional rehabilitation. Herein, it is recognized that minimizing the patients bed stay and maximizing early activity brings greater functional benefits than prolonging a passive wait for improvements in the patient's condition. Additionally, the rehabilitation effect in the treatment process is important for restoring lost functions, maintaining employment or social roles and reducing several signs and symptoms of the disease.

A review of evidences for physiotherapy effectiveness, however, indicates some limitations related with the selection of the most effective forms of rehabilitation practices. This situation comes about through the lack of consistent credible research. Indeed, rehabilitation practices are often selected based on tradition and are not always supported by sufficient evidences for their use [49].

The American College of Rheumatology (ACR) strongly recommends in hip joint OA rehabilitation, exercises that stimulate the cardio-vascular system, resistance training, aquatic therapies and participation in organized forms of activity. ACR also recommends the employment of mobility aids (Zimmer frames, canes and walking sticks), the use of thermo-therapy treatments and psycho-social support. Of note, the TEP (Technical Expert Panel) has no guidelines for using balance exercises, or muscle strengthening exercises, tai chi or manual therapy [3].

After the family physician or Primary health care provider (PHC) qualifies hip joint pain patients for physiotherapy, the first activities should include palpation assessment (see Table 1) of the muscles that may be involved in the hip area pain. This should be a base for developing a plan of conduct describing the sequence of using massage, physiotherapy and kinesotherapy. This will also allow the care-giver to specify simple activities to be performed by the patient alone at home so as to actively and responsibly attend to self-therapy, using skills of self-massage, self-physiotherapy and self-kinesotherapy. Such an approach to hip-joint pain mediation will permit to intensify physiotherapy in the frames of primary health care, but an additional beneficial effect of active self-engagement in the rehabilitation process is an education element: they learn what relieves pain and what hastens recovery. Furthermore, through self-therapy, patients take charge of their own recovery and improve muscular efficiency by stimulating angiogenesis and regenerative and repair processes. For this purpose, patients should perform daily simple recommended physiotherapeutic activities. These may 
be additionally supported by simple instructions in the form of brochures or video clips. In cases wherein joint changes have already occurred, activities at the primary health level are to support patients before they visit specialist clinics (rehabilitation or orthopedic) [53].

Introducing and undertaking education programs at the primary health care level requires systematic solutions and reorganization of present treatment practices. The model of conduct presented above, for patients with initial clinical symptoms of the hip joint degenerative changes, is supported by reports from other publications that indicate that in cases of advanced changes, the effectiveness of proposed non-pharmacological methods based on physiotherapy do not bring fully satisfying therapeutic effects. Hence, scientific evidences are presented as conditional to adopt and to use clinically [73]. However, introducing such programs, is cheaper than the costs of direct treatment (surgery) and its indirect effects (work-place absence, disability, restricted social role performance).

The success of the rehabilitation process depends not only on the proposed rehabilitation methods, but also on the patients' knowledge, their education and engagement level. Fully supervised or partially-supervised interventions may be effective in treating joint degenerative disease, but the patients' preferences for supervision level and the exercises course may be key prediction factors in observance of exercises and the bettering of treatment results [74].

The attractiveness of the proposed activity is also important, as are skills and readiness to participate in own healing. The study authors, in pursuing solutions to enhancing the effectiveness of physiotherapy, have placed attention upon the factors related to proper levels of blood supply and structure innerving that directly affect the hip joint function. The muscles that move joints do so through respective stimulation of the nervous system, so their efficiency depends on three components. An efficient muscle is a muscle well-nourished, well oxygenated and well-stimulated.

In considering the appropriate rehabilitating procedure, initially the need is to restore, e.g. using massage, suitable blood supply in accordance with the anatomy of vessels located in the hip joint area. Subsequently, it is recommended to apply other treatments appropriate to resolving currently dominating symptoms. The intent is to make better - not to make the condition worse. The authors of this publication agree with the conclusions drawn within other publications that further researches must be performed to to specify clinical phenotypes and definitions of early symptoms for $\mathrm{OA}$, to effectively prescribe physiotherapeutic recommended interventions at different stages of the disease advancement and to ascertain their effectiveness in treating patients with hip joint degenerative disease $[1,43,74]$.

Source of funding: This work was funded by the authors' own resources.

Conflict of interest: The authors declare no conflict of interests.

\section{References}

1. Zacharias A, Green RA, Semciw Al, et al. Efficacy of rehabilitation programs for improving muscle strength in people with hip or knee osteoarthritis: a systematic review with meta-analysis. Osteoarthritis Cartilage 2014; 22(11): 1752-1773.

2. Sekiya JK, Safran MR, Ranawat AS, et al. Artroskopia stawu biodrowego. Wrocław: Elsevier Urban \& Partner; 2013.

3. Hochberg MC, Altman RD, April KT, et al. American College of Rheumatology 2012 recommendations for the use of nonpharmacologic and pharmacologic therapies in osteoarthritis of the hand, hip and knee. Arthritis Care Res 2012; 64(4): 465-474.

4. Iwaniszczuk A, Majchrowska-Kaliś A, Kulinski W. Analiza postępowania fizykalnego w chorobie zwyrodnieniowej stawów biodrowych. Kwart Ortop 2011; 2: 108-121 (in Polish).

5. Boesen M, Ellegaard K, Henriksen M, et al. Osteoarthritis year in review 2016: imaging. Osteoarthritis Cartilage 2017; 25(2): $216-226$.

6. Hochschild J. Anatomia funkcjonalna dla fizjoterapeutów. Wrocław: MedPharm; 2018 (in Polish).

7. Harris-Hajes M, Mueller MJ, Sahrmann SA, et al. Persons with chronic hip joint pain exhibit reduced hip muscle strength. $J$ Orthop Sports Phys Ther 2014; 44(11): 890-898.

8. Shrier I. Muscle dysfunction versus wear and tear as a cause of exercise related osteoarthritis: an epidemiological update. Br J Sport Med 2004; 38(5): 526-535.

9. Woolf AD, Pfleger B. Burden of major musculosceletal conditions. Bull World Health Organ 2003; 81: 646-656.

10. French SD, Bennell KL, Nicolson PJA, et al. What do people with knee or hip osteoarthritisneed to know? An international consensus list of essential statements for osteoarthritis. Arthritis Care Res 2015; 67(6): 809-816.

11. Smink AJ, Bierma-Zeinstr SM, Schers HJ, et al. Non-surgical care in patients with hip or knee osteoarthritis is modestly consistent with a stepped care strategy after its implementation. Int J Qual Health Care 2014; 26(4): 490-498.

12. Hofstede SN, Vliet Vlieland TPM, Van de Ende CHM, et al. Variation in use of non-surgical treatments among osteoarthritis patients in orthopaedic practice in the Netherlands. BMJ Open 2015; 5(9): e009117, doi: doi:10.1136/bmjopen-2015-009117.

13. Quintana JM, Arostegui I, Escobar A, et al. Prevalence of knee and hip osteoarthritis and the appropriateness of joint replacement in an older population. Arch Intern Med 2008; 168(14): 1576-1584.

14. Rajkowska-Labon E, Kassolik K, Andrzejewski W, et al. Choroba zwyrodnieniowa stawów biodrowych: obraz kliniczny i postępowanie fizjoterapeutyczne. Rehabil Prakt 2017; 3: 52-60 (in Polish).

15. Igissinov N, Baimagambetov S, Batpen A. Evolutionary epidemiological assessment of coxarthrosis incidence among adults population in Kazakhstan. World App/ Sci J 2013; 24(9): 1271-1275.

16. Gay C, Chabaud A, Guilley E, et al. Educating patients about the benefits of physical activity and exercise for their hip and knee osteoarthritis. Systematic literature review. Ann Phys Rehabil Med 2016; 59: 174-183.

17. Stanisławska-Biernat E. Społeczne i ekonomiczne aspekty choroby zwyrodnieniowej stawów. Pol Arch Med Wewn 2008; 118(Suppl.): 50-52 (in Polish).

18. Foley B, Cleveland RJ, Renner JB, et al. Racial differences in associations between baseline patterns of radiographic osteoarthritis and multiple definitions of progression of hip osteoarthritis: the Johnston County Osteoarthritis Project. Arthritis Res Ther 2015; 17: 366-377.

19. Appleton CT. Osteoarthritis year in review 2017: biology. Osteoarthritis Cartilage 2018; 26(3): 296-303, doi: https://doi.org/10.1016/j. joca.2017.10.008.

20. Rąpała K, Walczak P, Truszczyńska A. Etiopatogeneza choroby zwyrodnieniowej stawu biodrowego. Kwart Ortop 2011; 4: 386-395 (in Polish).

21. Liu J, Cai W, Zhang HX, et al. Rs143383 in the growth differentiation factor 5(GDF5) gene significantly associated with Osteoarthritis (OA) - a comprehensive meta-analysis. Int J Med Sci 2013; 10(3): 312-319.

22. Ahedi HG, Aitken DA, Blizzard LC, et al. Correlates of hip cartilage defects: a cross-sectional study in older adult. J Rheumatol 2016; 43(7): 1406-1412. 
23. Varady PA, Glitsch U, Augat P. Loads in the hip joint during physically demanding occupational tasks: a motion analysis study. J Biomech 2015; 48(12): 3227-3233.

24. Magnus T. Former male elite athletes have a higher prevalence of osteoarthritis and arthroplasty in the hip and knee than expected. Am J Sports Med 2012; 40(3): 527-533.

25. Vigdorchik JM, Nepple JJ, Eftekhary N, et al. What is the Association of Elite Sporting Activities with the development of hip osteoarthritis? Am J Sports Med 2017; 45(4): 961-964.

26. Alentorn-Geli E, Samuelsson K, Musahl V, et al. The Association of Recreational and Competitive Running with hip and knee osteoarthritis: a systematic review and meta-analysis. J Orthop Sports PhysTher 2017; 47(6): 373-390.

27. Lefèvre-Colau MM, Nguyen C, Haddad R, et al. Is physical activity, practiced as recommended for health benefit, a risk factor for osteoarthritis? Ann Phys Rehabil Med 2016; 59: 196-206.

28. Zacharias A, Green RA, Semciw A, et al. Atrophy of hip abductor muscles is related to clinical severity in a hip osteoarthritis population. Clin Anat 2018; 31(4): 507-513, doi: 10.1002/ca.23064.

29. Shih M, Hootman JM, Kruger J, et al. Physical activity in men and women with arthritis National Health Interview Survey, 2002. Am J Prev Med 2006; 30: 385-393.

30. Muklewicz E, Sierakowski S, Klimiuk PA, et al. Diagnostyka radiologiczna w chorobie zwyrodnieniowej stawów. Próby klasyfikacji obrazu radiologicznego. Nowa Med 2002: 2: 17-20 (in Polish).

31. Nalazek A, Kaminska E, Kaźmierczak U, et al. Leczenie, diagnostyka i profilaktyka stawu biodrowego w chorobie zwyrodnieniowej. $J$ Health Sci 2014; 4(1): 333-338 (in Polish).

32. Ferguson SJ, Bryant JT, Ito K. An in vitro investigation of the acetabular labral seal in hip joint mechanics. J Biomech 2003; 36(2): 171-172.

33. Dandacheli W, Kannan V, Richards R, et al. Analysis of cover of the femoral head in normal and dysplastic hip: new CT - based technique. J Bone Joint Sur Br 2008; 90(11): 1428-1434.

34. Muratha PE, Hafez MA, Jaramaz B, et al. Variations in acetabular anatomy with reference to total hip replacement. J Bone Joint Surg Br 2008; 90(3): 308-313.

35. Neogi T. The Epidemiology and impact of pain in osteoarthritis. Osteoarthritis Cartilage 2013; 21(9): 1145-1153.

36. Sanchez HC, Bay-Jensen AC, Mobasheri A. A osteoarthritis biomarkers derived from cartilage extracellular matrix: current status and future perspectives. Ann Phys Rehabil Med 2016; 59: 145-148.

37. Bennell KL, Hinman RS. A review of the clinical evidence for exercise in osteoarthritis of the hip and knee. J Sci Med Sport 2011; 14: 4-9.

38. Kanavaki AM, Rushton A, Efstathiou N, et al. Barriers and facilitators of physical activity in knee and hip osteoarthritis: a systematic review of qualitative evidence. BMJ Open 2017; 7: e017042, doi: 10.1136/bmjopen-2017-017042.

39. Department of Veterans Affairs, Department of Defense. VA/DoD clinical practice guideline for the non-surgical management of osteoarthritis. The Office of Quality and Performance, VA, Washington, DC, Office of Evidence Based Practice, US Army Medical Command; 2014: 1-126.

40. Andrzejewski W, Kassolik K. Ocena palpacyjna w masażu tensegracyjnym. Fizjoter 2009; 17(4): 60-66 (in Polish).

41. Andrzejewski W, Kassolik K, Cymer K. Poziom korelacji między wrażliwością uciskową mierzoną na przyczepie kostnym i na przebiegu mięśni szkieletowych. Fam Med Prim Care Rev 2009; 11(2): 127-133 (in Polish).

42. Travell JG, Simons DG. Myofascial pain and dysfunction the trigger point manual. Baltimore: Williams \& Wilkins; 1984.

43. Iversen MD. Managing hip and knee osteoarthritis with exercise: what is the best prescription? Ther Adv Muscoscelet Dis 2010; 2(5): 279-290.

44. Kuciel-Lewandowska J, Marcinkiewicz N, Kierzek A, et al. Zdrowy tryb życia a choroba zwyrodnieniowa stawów. Acta Bio-Opt Inform Med 2012; 18(4): 229-233 (in Polish).

45. Veenhof C, Huisman PA, Barten JA, et al. Factors associated with physical activity in patients with osteoarthritis of the hip or knee: a systematic review. Osteoarthritis Cartilage 2012; 20(1): 6-12.

46. World Health Organization. Therapeutic patient education. Continuing education programmes for health care providers in the field of prevention of chronic diseases. Copenhagen: World Health Organization Regional Office for Europe; 1998.

47. Kassolik K, Andrzejewski W. Masaż tensegracyjny. Fizjoter 2010; 18(1): 66-71 (in Polish).

48. Kassolik K, Andrzejewski W. Masaż tensegracyjny. Wrocław: MedPharm; 2014 (in Polish).

49. Nguyen C, Lefèvre-Colau MM, Poiraudeau S, et al. Rehabilitation (exercise and strength training) and osteoarthritis: a critical narrative review. Ann Phys Rehabil Med 2016; 59: 190-195.

50. Foley A, Halbert J, Hewitt $\mathrm{T}$, et al. Does hydrotherapy improve strength and physical function in patients with osteoarthritis - a randomised controlled trial comparing a gym based and a hydrotherapy based strengthening programme. Ann Rheum Dis 2003; 62: $1162-1167$.

51. Silva LE, Valim V, Pessanha AP, et al. Hydrotherapy versus conventional land-based exercise for the management of patients with osteoarthritis of the knee: a randomized clinical trial. Phys Ther 2008; 88(1): 13-21.

52. Cunningham NR, Kashikar-Zuck S. Nonpharmacologic treatment of pain in rheumatic diseases and other musculoskeletal pain conditions. Curr Rheumatol Rep 2013; 15(2): 306-320.

53. Iliewva EM, Oral A, Kucukdeveci A, et al. Osteoarthritis. The role physical and rehabilitation medicine physicians. The European perspective based on the best evidence. A paper by the UEMS-PRM Section Professional Practice Committee. Eur J Phys Rehabil Med 2013; 49: 579-593.

54. Poulsen E, Hartvigsen J, Christense HW, et al. Patient education with or without manual therapy compared to a control group in patients with osteoarthritis of the hip. A proof-ofprinciple three-arm parallel group randomized clinical trial. Osteoarthritis Cartilage 2013; 21(10): 1494-1503.

55. Kassolik K, Kurpas D, Wilk I, et al. The effectiveness of massage in therapy for obturator nerve dysfunction as complication of hip joint alloplasty - case report. Rehabil Nurs 2014; 39(6): 311-320.

56. Robertson V, Ward A, Low J, et al. Fizykoterapia. Aspekty kliniczne i biofizyczne. 4th ed. Wrocław: Elsevier Urban and Partner; 2009 (in Polish).

57. Iversen MD. Rehabilitation interventions for pain and disability in osteoarthritis. Am J Nurs 2012; 3(Suppl. 1): 32-37.

58. Conaghan P, Birell F, Burke M, et al. Osteoarthritis. National clinical guidelines for care and management in adults. National Collaborating Centre for Chronic Conditions (UK). London: Royal College of Physicians; 2008.

59. Koybasi M, Borman P, Kocaoglu S, et al. The effect of additional therapeutic ultrasound in patient with primary hip OA: a randomized placebo - controlled study. Clin Rheumatol 2010; 29: 1387-1394.

60. Pisula-Lewandowska A. Zastosowanie fizykoterapii w artrozie stawu biodrowego. Prakt Fizjoter Rehabil 2012; 27 : 10-15 (in Polish).

61. Lisiński P, Andrzejewska J, Samborski W. Próba weryfikacji subiektywnych objawów u chorych z chorobą zwyrodnieniową stawów biodrowych poddanych kinezyterapii. Baln Pol 2006; 2: 111-115 (in Polish). 
62. Krauss I, Katzmarek U, Rieger MA, et al. Motives for physical exercise participation as a basis for the development of patient-oriented exercise interventions in osteoarthritis: a cross-sectional study. Eur J Phys Rehabil Med 2017; 53(4): 590-602.

63. Marks R. Osteoarthritis and physical activity participation: a complex issue requiring multiple inputs. EC Orthopaedics 2016 4.6: $681-$ $-687$.

64. Reiman MP, Bolgla LA, Loudon JK. A literature review of studies evaluating gluteus maximus and gluteus medius activation during rehabilitation exercises. Osteoarthritis Cartilage 2014; 22(11): 1752-1773.

65. Regnaux JP, Lefèvre-Colau MM, Trinquart L, et al. High-intensity versus low-intensity physical activity or exercise in people with hip or knee osteoarthritis. Cochrane Database Syst Rev 2015; 29; 10: CD010203, doi: 10.1002/14651858.CD010203.

66. Jensen C, Roos EM, Kjærsgaard-Andersen $\mathrm{P}$, et al. The effect of education and supervised exercise vs. education alone on the time to total hip replacement in patients with severe hip osteoarthritis. A randomized clinical trial protocol. BMC Musculoskeletal Disorders 2013; 14: 21-29.

67. Fransen M, McConnell S, Hernandez-Molina G, et al. Exercise for osteoarthritis of the hip (Review). Cochrane Database Syst Rev 2014; 4: CD007912, doi: 10.1002/14651858.CD007912.

68. Hootman JM, Macera CA, Helmick CG, et al. Influence of physical activityrelated joint stress on the risk of self-reported hip/knee osteoarthritis: a new method to quantify physical activity. Prev Med 2003; 36: 636-644.

69. Guideline for the non-surgical management of hip and knee osteoarthritis. Melbourne: The Royal Australian College of General Practitioioners; 2009.

70. Gieremek K, Janicki S, Przeździak B, et al. Wyroby medyczne. Zaopatrzenie indywidualne. Warszawa: Wydawnictwo Lekarskie PZWL; 2016 (in Polish).

71. Przeździak B, Nyka W. Zastosowanie kliniczne protez, ortez i środków pomocniczych. Gdańsk: Via Medica; 2008 (in Polish).

72. Fryer G. Muscle energy technique: an evidence-informed approach. Int J Osteopath Med 2011; 14(1): 3-9.

73. Bennell KL, Egerton T, Martin J, et al. Effect of physical therapy on pain and function in patients with hip osteoarthritis: a randomized clinical trial. JAMA 2014; 311(19): 1987-1997.

74. Wellsandta E. Golightlyb Y. Exercise in the management of knee and hip osteoarthritis. Curr Opin Rheumatol 2018; 30: 151-159.

Tables: 2

Figures: 0

References: 74

Received: 26.04.2018

Reviewed: 03.05.2018

Accepted: 04.05.2018

Address for correspondence:

Krzysztof Kassolik, MD, PhD, Assoc. Prof.

Wydział Fizjoterapii AWF

Al. I.J. Paderewskiego 35

51-612 Wrocław

Polska

Tel.: +48 71 347-30-89

E-mail: krzysztof.kassolik@awf.wroc.pl, krzysztof.kassolik@gmail.com 